\title{
A Morte na Infância e sua Representação para o Médico - Reflexões sobre a Prática Pediátrica em Diferentes Contextos
}

\section{Infant Death and its Representation for the Physician - Reflections about Pediatric Practice in Diferent Contexts}

\section{Leandro Hoffmann ${ }^{1}$}

HOFFMANN, L. Infant Death and its Representation for the Physician - Reflections about Pediatric Practice in Diferent Contexts. Cad. Saúde Públ., Rio de Janeiro, 9 (3): 364-374, jul/sep, 1993.

Death - this certainty, which is directly or indirectly present somewhere in every human being's life - has been a forbidden, denied, and forgotten matter, especially in the twentieth century.

Although physicians have a closer experience with death through their daily professional contact, they are unable to become familiar with it, although facing this reality always provokes conflicting feelings like defeat, guilt, and impotence.

In spite of the traditional silence on this matter in medical schools, it is important to introduce discussions about death and dying in the medical school curriculum. This idea was suggested by all the interviewees and we completely agree with it. It may facilitate the process of understanding death as an integral part of life and promote humanization in caring for dying patients and their families.

Key words: Attitude to Death; Ethics, Medical; Physician's Role; Pediatrics; Death; Child

\section{INTRODUÇÃO}

A morte, embora presente direta ou indiretamente em algum momento da vida de todo ser humano, não é uma questão fácil de ser discutida, principalmente em nossa cultura. Parece que somos condicionados a não aceitar a morte como uma etapa normal em nossas vidas.

Os médicos, apesar de uma relação mais próxima com a morte, através da sua vivência profissional cotidiana, não conseguem se familiarizar com ela. Diversas vezes, após uma tentativa frustrada de reanimar um paciente e frente à inevitabilidade da morte, pude observar, por trás de uma apresentação fria e técnica, um misto de sentimentos de impotência, culpa, fracasso, medo e, principalmente, a dificuldade e o despreparo para lidar com a situação, com as pessoas e com os sentimentos envolvidos.

${ }^{1}$ Rua Fagundes Varela 515, apto. 904, Niterói, RJ, 24210-520, Brasil.
Se, por um lado, a relação dos médicos com a morte é, na maioria das vezes, complexa, a morte na infância é revestida de especial crucialidade. A abordagem da morte de uma criança reveste-se de particular fonte de angústia para o pediatra. Neste caso, parece que toda a angústia inerente à situação é vivida de maneira exacerbada.

As diferentes representações da morte da criança para o médico, suas próprias concepções de morte e as diferentes formas de se abordar os questionamentos a ela associados constituem o objeto desta análise.

Trabalhei com a questão da morte na infância por ser a Pediatria minha área de atuação. Apesar disso, a discussão abrangeu a representação da morte de uma forma geral, não se restringindo apenas à questão da infância.

Utilizei a metodologia da investigação qualitativa para dar conta de compreender a representação da morte na vida do médico, sempre buscando conhecer como se deu a evolução desta representação ao avaliar a discussão sobre 
a morte na formação pessoal de cada indivíduo, bem como na própria formação médica. $\mathrm{O}$ instrumento principal do trabalho de campo foram entrevistas abertas, através das quais trabalhei com a análise do discurso e com o relato de experiências. $\mathrm{O}$ estudo inclui quatro grupos diferentes de médicos: médicos de serviço de emergência, médicos do Centro de Tratamento Intensivo (CTI), médicos oncologistas e médicos homeopatas com vivência com pacientes terminais. Apesar das diferentes vivências, inclusive no contexto social em que atuam, das diversidades na formação e da própria experiência de vida particular de cada profissional, busquei utilizar estas contradições e divergências, produzindo um material de reflexão que permitiu o desenvolvimento, a fundamentação e o alcance dos objetivos da pesquisa.

\section{OS MÉDICOS E A MORTE — FORMAÇÃO E PRÁTICA MÉDICA}

Ao analisarmos a relação dos médicos com a morte, não podemos deixar de considerar esta representação fora da prática médica. $\mathrm{Na}$ nossa sociedade, a morte é tratada como um tema interditado, o que traduz toda uma forma de pensar e sentir a morte, que se apresenta para nós com um sentido que parece ser absoluto e definitivo. Assim sendo, a morte é representada pelo pavor e pela necessidade imperativa e quase ritualizada da negação.

No entanto, é importante observar que a morte nem sempre teve este significado que nós atribuímos a ela atualmente. Em nossa própria cultura, já houve épocas em que o homem defrontou-se melhor com a morte. Contudo, foram ocorrendo transformações lentas e profundas que culminaram na representação atual.

Em termos históricos, as atitudes frente à morte sofreram transformações dramáticas através dos séculos. Alguns historiadores, especialmente dentro da corrente denominada história das mentalidades, dedicaram-se ao estudo destas transformações. Ariès (1982; 1988), um destes autores, assinala que, inicialmente, os homens não temiam a morte. As pessoas freqüentemente eram avisadas e sabiam como e quando iam morrer. A morte era aceita sem medo, como sendo parte integrante da vida e do destino coletivo. A morte não era nem apressada nem postergada. $\mathrm{O}$ moribundo era $\mathrm{O}$ protagonista da tradicional cerimônia de morte. Ele conhecia e presidia todo o protocolo envolvido nesta cerimônia. $\mathrm{O}$ ato de morrer era um evento público que se dava na presença da família, amigos, vizinhos e, inclusive, das crianças.

Da Idade Média a meados de século XIX, a atitude frente à morte foi deixando de ser algo trivial, comum, esperado e aceito, tornando-se algo era vergonhoso e proibido. Assim sendo, na Idade Moderna, a morte problematizou-se. Toda a concepção que nasce das novas relações de produção, das descobertas, do desenvolvimento da ciência e do surgimento do capital como força principal de produção representa exatamente o contrário do que afirmava-se na Idade Média. Nessa época, a promessa de vida eterna prolongava e ampliava o destino humano. Enquanto que, para a sociedade moderna, o homem vivo pode quase tudo, morto ele não é mais nada, não significa mais nada. Surge então a representação da morte enquanto fracasso, frustração, pois ela interrompe e interfere no projeto do homem moderno, um homem decidido a dominar e a transformar o mundo. Em virtude disso, vai havendo um movimento de silêncio em torno da morte, do homem que morre e do homem morto, chegando-se, assim, a esta representação atual, que envolve a questão da morte em interdição, tabu, proibição e silêncio.

O movimento de negação pode ser sentido no início de cada entrevista frente à apresentação do tema morte. A resposta básica e quase imediata dos entrevistados foi de surpresa e certo desconforto. Este espanto traduz uma ausência de reflexão sobre a morte, sentida como algo estranho, como se ela não fizesse parte de uma vivência cotidiana, tanto profissional como humana. Vejamos o seguinte depoimento:

- Falar de morte não é uma coisa normal, mesmo pensando que tudo o que existe na vida deveria ser discutido. Mas falar de morte é diferente, não sei o que dizer, não me sinto preparada e, de qualquer modo, é algo doloroso, que a gente traz mal resolvido. 
O processo de socialização não concebe a morte e não prepara os indivíduos para sua vivência. Com isso, vai sendo progressivamente incorporada uma imagem negativa, cheia de ansiedade e de questões não-respondidas, nãocompreendidas e não-aceitas.

Podemos concluir que o despreparo sentido pelos médicos e por outros profissionais de saúde na abordagem da questão da morte antecede a própria formação profissional, iniciando-se já na infância a construção do silêncio. O despreparo para lidar com a morte pode ser resumido na seguinte fala de uma entrevistada:

- Você não teve este preparo na sua vida. Você não consegue metabolizar isso nem no nível pessoal, quanto mais ao nível profissional.

O primeiro contato do estudante de medicina com a questão da morte ocorre durante o curso de anatomia. Questões pessoais e emoções podem ser desencadeadas pela dissecação de cadáveres. Uma questão freqüente é o sentimento de identificação:

- Para mim, foi muito difícil. É como se cada corpo daquele se parecesse um pouco comigo ou com alguém muito próximo.

Contudo, parece que o processo de identificação precisa ser evitado:

- A gente primeiro recebeu os pedaços. Eu me lembro, acho que era até para preparar, para não ver o todo e não se identificar.

Maria Helena Villas Boas Concone, no trabalho intitulado "O 'Vestibular' de Anatomia", postula que o papel desta disciplina no currículo médico transcende ao objetivo de conhecimento do corpo humano, funcionando também como um "rito de iniciação":

"De modo geral, os primeiros contatos com a Anatomia, embora esperados com sofreguidão, pois implicam estar entrando realmente na Medicina, implicam também em sofrimento. $O$ sofrimento e a superação do sofrimento não são apenas importantes para aquisição do conhecimento e das atitudes adequadas, como são, em si mesmos, parte das atitudes necessárias" (Concone, 1983).
Sapir (1972) adverte que, através do encontro com o cadáver, iniciam-se, nos alunos, mecanismos de defesa indispensáveis para a futura profissão. Podemos evidenciar a percepção deste processo, mesmo que de forma inconsciente, através da seguinte fala:

- A sala de Anatomia tinha alguma coisa de diferente dos demais laboratórios, e sempre que eu entrava ali me sentia angustiada, não sei exatamente porquê, mas de certa forma eu sabia que tinha de superar isso.

Assim, o processo de formação do médico tende a imprimir uma visão impessoal e puramente biológica da questão da morte, conforme evidencia a fala de um estudante de medicina, citado por Barton et al. (1972):

"Aquele primeiro corte através da pele [de um cadáver] é realmente péssimo. Mas à medida em que você aprofunda, aquilo começa a se parecer um livro de Anatomia e não lembra mais um ser humano, você vê que não é tão mal" (Barton et al., 1972).

Embora a literatura aborde a problemática dos médicos em se relacionarem com a morte e com pacientes terminais, as escolas médicas não se manifestam sobre a necessidade de discussão desta temática.

A questão morte e formação médica, presente no roteiro das entrevistas, determinou a seguinte conclusão: apesar de mais próximos desta realidade, em sua prática cotidiana,os médicos efetivamente não são preparados para esta vivência. Alguns admitem isso como uma falha curricular, onde a abordagem é voltada para a doença e para a cura. Todos assinalam a importância da presença desta discussão na formação médica. Todos evidenciam sua relevância no conhecimento dos sentimentos envolvidos no contato com pacientes terminais e sua abordagem.

Em relação a esta temática, os depoimentos dos entrevistados são claros, conclusivos e suficientes, dispensando maiores interpretações:

- Na faculdade nunca ninguém falou de morte, nem atestado de óbito eu nunca vi. Nunca me ensinaram a preencher um atestado de óbito, que é uma coisa superobjetiva, quanto mais me 
questionar acerca do que eu sentia, do que o paciente sentia, do que a família sentia frente ao confronto com a morte.

- A gente precisava aprender mais sobre a morte, sobre como lidar com a morte, sobre como lidar com as pessoas envolvidas com a morte, questionar o nosso próprio envolvimento. Isto é muito importante e a gente não sabe. Temos muita dificuldade.Tinha que haver alguma coisa neste sentido em nossa formação.

- Na faculdade, a gente tem basicamente uma orientação técnica. A gente aprende Fisiologia, Farmacologia e Patologia o tempo todo. O nível de questionamento é zero. Você sai da faculdade sem conhecer e saber lidar com a problemática humana. E faz parte de todo homem, a vida, a morte,o sofrimento e todos os aspectos a eles relacionados.Eu acho que a gente sai muito despreparado.

- Na minha formação e na formação em geral, eu sinto que a morte é um tema ausente. Penso que para se falar na relatividade da morte, obrigatoriamente terá que se discutir a relatividade do conhecimento médico, do conhecimento técnico,o que é absolutamente indiscutível. Nunca se discute a adequação do nosso conhecimento. A técnica é a melhor maravilha que existe hoje no mundo, e é graças a ela que as pessoas sobrevivem. Teria que se discutir por que morrem crianças com sarampo se existe uma vacina. $E$ discutir por que nos $C T I s$ não há vagas. Teria que se discutir a onipotência médica, pois toda a concepção se baseia na capacidade do médico em deter a morte. Os conhecimentos que não temos hoje alcançaremos mais cedo ou mais tarde e seremos capazes, enfim, de deter a morte. E falar sobre a morte coloca tudo isso em questão. Mas é muito importante abrir este espaço,pois a morte causa muito sofrimento, principalmente se a gente não pode falar dele.

- Lugar da morte no curso médico? Nenhum, mas nenhum mesmo. Nunca se fala nada. Morreu, empacotou, e acabou.

\section{A MORTE NA INFÂNCIA}

A maioria das pessoas assume uma dificuldade maior em relação à morte da criança. Isso traduz a representação dominante, a idéia de que a morte na infância é vida frustrada, é vida desprovida de sentido. Tal concepção é decorrente do próprio sentido que, em nossa cultura, se dá à vida do homem. Sendo o homem visto como um meio de produção e consumo, uma criança que morre estaria sendo frustrada no sentido de sua vida. Esta idéia encontra-se desenvolvida na seguinte fala de um entrevistado:

- Quando se pensa em morte na infância, se pensa em morte precoce, porque a idade de morrer é a idade da velhice. A criança nasce e se desenvolve para chegar à idade adulta. $O$ adulto é o objetivo de tudo. Então ele realiza as coisas que tem de realizar, fica velho e morre. Assim sendo,em nossa concepção, a morte da criança é realmente prematura, e por isso somos pediatras, para evitar esta morte precoce. Tal visão está por trás de uma ideologia de que a infância é uma idade passageira, que o objetivo da criança é ser adulto, quando na verdade, seu objetivo deveria apenas ser criança e viver intensamente o sentido de ser criança.

Em relação à morte de uma criança, Zaidhaft (1990) enumera algumas hipóteses para explicar essa dor maior entre os que ficam: "pelo ciclo de vida que não se teria cumprido; por ela ser desprotegida; por ser depositária do nosso narcisismo; por ser símbolo de nossa imortalidade que se vai". Alguns depoimentos evidenciam esta dificuldade, este sofrimento mais acentuado:

- Eu acho que em todas as famílias quando morre uma criança, alguma coisa foi roubada das próprias pessoas, mas principalmente daquela pessoa em si, que tinha muito a dar".

- A morte na Pediatria é muito mais complicada. Com um velhinho é diferente, ele sabe que está perto da morte, é mais fácil de aceitar. A criança é diferente, ela quer viver e correr atrás da pipa, do picolé.É aquela energia. Acho inconcebível.

- A criança tem um poder de regeneração enorme. Às vezes está queimando de febre e mesmo assim está pulando, e no dia seguinte não tem mais nada. Então, quando a gente encontra um potencial degenerativo numa criança, como câncer, AIDS, não combina, soa mais pesado do que em um adulto com doença grave. 
- A morte na infância? Não consigo aceitar, acho uma tremenda injustiça.

\section{VIVÊNCIAS DE EMERGÊNCIA E CTI}

Em geral, é neste cenário das emergências e CTIs que ocorre a maioria das mortes em nosso meio atualmente. Longe de, pela repetição e pelo hábito, a morte tornar-se familiar, ela é sempre uma fonte de estresse emocional para médicos e outros profissionais de saúde.

$\mathrm{O}$ questionamento que freqüentemente abre as discussões deste espaço situa-se em torno das decisões que, na maioria das vezes, o médico tem de tomar em relação à vida das pessoas sob seus cuidados. Muitas vezes cria-se um verdadeiro dilema, decorrente do surgimento de um incrível arsenal tecnológico para o enfrentamento da morte, obrigando o médico a um enfrentamento ético e ideológico sobre a sobrevivência e a morte.

Nas últimas décadas, avanços fantásticos da tecnologia marcaram a história da Medicina. Embora o objetivo de tais inovações seja o prolongamento da vida, muitas vezes isto não é alcançado. O que ocorre, freqüentemente, é apenas uma modificação e um prolongamento do processo de morrer. Com isso, muitas vezes o desligamento de uma máquina é a causa imediata da morte, em substituição ao processo natural de falecimento das funções fisiológicas (Baltzel, 1971).

Um ponto marcante neste questionamento é a problemática da reanimação. Parece que, mesmo quando a morte é inevitável, ela é sempre inconcebível e precisa ser no mínimo adiada. Meagher \& Leff (1987) assinalam que o princípio médico da incerteza postula que existe sempre alguma coisa a mais que poderia ser feita:

"A incerteza é solucionada fazendo-se mais alguma coisa. $O$ imperativo tecnológico exige que qualquer coisa deve ser feita. Dentro deste princípio não há como evitar terapias agressivas e invasivas. Deve haver sempre mais alguma coisa que a gente possa fazer ou tentar. Estes princípios parecem assumir maior relevância quando o paciente é uma criança. É muito mais difícil para os médicos, deixarem a morte levar uma criança. A criança merece um futuro, uma vida longa. A morte deve ser retardada a todo custo" (Meagher \& Leff, 1987:184-185).

Nos depoimentos dos entrevistados, o momento da reanimação é muitas vezes associado a um "papel", a uma "obrigação" que o médico tem de desempenhar no "drama" da morte. Este papel deve ser desempenhado incondicionalmente, independente da possibilidade de um resultado positivo ou não. Vejamos um exemplo:

- Eu faço tudo, sempre. Mesmo quando chegam aqueles "defuntinhos". É como se fosse um ritual. Toda aquela encenação, da adrenalina, bicarbonato, ambu (Drogas e aparelhos usados na reanimação). Aqui no hospital a gente tem poucos recursos, então parece um teatro, é tudo chutado, tem toda uma encenação... Quase todas as batalhas que eu travei com a morte eu perdi. Mas é uma coisa da nossa formação: a morte é uma adversária e a gente tem que combatê-la.

Muitas vezes esta encenação pode funcionar como uma defesa para lidar com a problemática da morte:

- A morte tem um certo teatro também. Então eu peguei o neném já morto. Passei um tubo traqueal e fui conversar com a mãe: "Olha, seu neném está muito mal..." A mãe entrou na sala chorando, desesperada, e eu estava ventilando a criança e me coloquei na frente da mãe para que ela não visse que a criança estava morta. $E$ fui fazendo um teatro mesmo, e nestas horas a gente faz, a gente tem de fazer. E a mãe desesperada, enquanto eu aumentava progressivamente a gravidade da criança, até que disse: "olha o seu neném morreu, mas eu fiz o possível e você viu que eu fiz tudo." Quer dizer, é um teatro.

Se a questão da tecnologia pode trazer um problema de ética, a ausência ou limitação de recursos tecnológicos também coloca nas mãos dos profissionais decisões como a de ter que escolher a quem beneficiar.

- Eu já passei por uma situação na qual tive que escolher qual paciente deveria reanimar. Tive 
dois pacientes que apresentaram parada cardíaca ao mesmo tempo e só havia um ambu, e eu tive que escolher qual paciente deveria reanimar. Foi uma escolha técnica, se é que isso é possível. E escolhi o que tinha mais chances de sobrevida. E, no final das contas, nenhum dos dois sobreviveu. O que eu escolhi morreu e o que eu não escolhi, também. Então, tem determinadas situações em que você se dota de poder. Eu questiono isso. Será que tenho poder para decidir isto? Quem vai morrer, quem vai continuar vivo? Acho que esta escolha é o fim da picada.

Através da análise do discurso deste grupo de médicos foi possível observar que os sentimentos, as atitudes e as próprias práticas presentes no confronto com a morte não são uniformes, variando de um médico para outro e de uma "morte" para outra. Assim sendo haveria mortes e mortes. Segundo Sudnow (1981), há dois modos de se considerar a morte num hospital: mortes esperadas, que são parte dos acontecimentos previstos num determinado setor do hospital; e mortes, não previstas, que simplesmente não poderiam acontecer.

Neste sentido, podemos perceber que determinados tipos de morte causam uma reação mais branda, sendo por vezes mais aceitos e mesmo desejados. Isto ocorre principalmente em relação aa crianças com qualidade de vida ruim, crianças com deficiência mental, crianças com quadro de desnutrição grave, quando evidenciase um desestímulo, uma falta de investimento para a abordagem da morte dos "deficientes" e da morte "social":

- Em relação à criança desnutrida, e não só o desnutrido, é diferente. Vamos chamar aqui de "miserável": tem os desnutridos graves, tem os neuropatas, tem os mongóis. Sinceramente, eu tenho sentido uma derrota mais suave, mais branda. Você não sai tão arrasado e muitas vezes até aliviado. Sabe, são quadros que você vê que não têm futuro. É duro de admitir, mas muitas vezes a gente se sente aliviado.

Muitos depoimentos insistem na questão do abandono, do afastamento e do desenvestimento:

- Essas crianças que já têm uma qualidade de vida ruim, quando vêm parar num CTI, eu pessoalmente não tenho a menor vontade de tratar delas, eu e a maior parte dos médicos de CTI. Mas isso não é uma decisão nossa, mas a tendência minha, de sentimento, é abandonar um pouco a criança. Eu trato dela pelo lado racional, mas de fato não tenho a menor vontade de tratar uma criança que tenha uma doença de base, ou uma síndrome genética, e que tenha a qualidade de vida ruim. Realmente, a gente se afasta e costuma investir menos nestes casos.

Por outro lado, existem mortes que são inconcebíveis, que jamais poderiam ocorrer. Nestes casos, a reação de desespero é exacerbada:

- Às vezes chegam crianças fortes, sadias e que morrem por uma besteira, tiveram um acidente qualquer, um engasgo por exemplo, é difícil de engolir. É muito mais doloroso.

Um fato particularmente interessante nos depoimentos sobre a morte é sua freqüente associação com termos e palavras referentes ao processo de digestão: engolir, descer, digerir, metabolizar. Rodrigues (1983) cita falas de civilizações que utilizam o canibalismo como procedimento funerário: "quando a gente não come os mortos fica angustiado. Se a gente come, fica tranqüilo, o coração não palpita". Além disso, o autor assinala a presença de algumas expressões em nossa linguagem que simbolizam estas práticas, expressões com as quais a sociedade ocidental sempre se escandalizou, por exemplo: papa-defuntos e sarcófago (que come carne). Segundo o autor, o "canibalismo funerário" "consiste em ao mesmo tempo separar o morto e com ele continuar em сотиnicação, não sendo necessariamente grave nem traumatizante" (Rodrigues, 1983:61). Neste sentido, retomamos os depoimentos de alguns entrevistados:

- Você não consegue metabolizar a morte nem a nível pessoal.

- Têm crianças bonitas, bem cuidadas e que morrem subitamente, sem explicação, é duro pra engolir.

- Morte de desnutrido e por problema social tem em todo plantão. É nosso feijão-com-arroz, desce mais leve. Acho que a gente até digere melhor que outras mortes. 
Outro dado interessante presente nos depoimentos confirma e corrobora toda uma ideologia de negação da morte. Trata-se da rapidez com que, freqüentemente, na maioria dos locais, as atividades funerárias são executadas. Em alguns hospitais, as atividades gerais, como exames complementares, serviços de limpeza, transferência de pacientes, entre outras, são executadas dentro de uma "margem de atraso" prevista. O "ocultamento" e "desaparecimento" das pessoas que acabam de morrer não podem esperar. Parece que a maioria das pessoas não consegue suportar a presença da morte. Temos, por um lado, os profissionais sufocados por um sentimento de fracasso; por outro lado, todas as pessoas próximas, inclusive os próprios profissionais, ameaçadas pela angústia de um processo de identificação. Esta situação é comentada por uma entrevistada:

- Muitas vezes você mal termina as atividades de reanimação e constata o óbito e você vira e procura o corpo, ele já desapareceu. Parece que as pessoas têm medo de se contaminar.

As decisões, como vimos, ficam exclusivamente a critério do médico. Porém, o poder decisório não é absoluto. Ele é determinado por vários fatores inerentes ao contexto sociocultural, do qual nunca pode ser desvinculado. A partir desta observação, poderíamos compreender as diferentes representações e afirmar que a decisão voltada estritamente para o lado técnico, embora possa ser eticamente a solução ideal, é, ao mesmo tempo, ilusória. Principalmente em se tratando da questão da vida e da morte, da qual é impossível dissociar o caráter humano e existencial. Dentro desta dicotomia poder e dúvida, vejamos o que sugere o padre Jean de la Croix Kelin:

"Existem não-intervenções que são homicidas, aquelas que privam o doente de chances reais de levar uma existência autenticamente humana, isto é, uma vida em que as relações interpessoais existam verdadeiramente $e$ onde a liberdade profunda pode ainda ser exercida. Existem não-intervenções que se impõem como um dever: são aquelas em que o paciente seria apenas um destroço humano, e igualmente aquelas que um paciente lúcido pediria, pelas razões já mencionadas, que não se prolongasse uma vida excessivamente dolorosa. (...) Talvez nos casos em que subsistem dúvidas graves o médico devesse perguntar a si mesmo se aconselharia a intervenção em se tratando de seu próprio filho, de um amigo muito caro, ou de si próprio" (Ziegler, 1977).

\section{A VIVÊNCIA COM DOENÇAS MALIGNAS}

Um aspecto importante na vivência dos oncologistas é a formação de um vínculo entre o médico, a criança e a família, ao contrário do que ocorre em ambientes de emergência e CTI, onde a carga horária, sob a forma de plantões, dificulta ou mesmo impede a formação de vínculos maiores. Apesar de ambos terem pacientes terminais sob seu cuidado e a presença da morte ser rotineira em sua prática, o significado e a representação desta vivência é diferente. A vivência ambulatorial com a morte, especificamente no casso de doenças malignas, é muito particular.

As emoções e sentimentos normalmente presentes no confronto do médico com a morte, tais como impotência, fracasso e identificação com reflexões sobre sua finitude, não ficam restritas ao momento da morte. Toda a angústia está presente, diluída e ao mesmo tempo concentrada, em todo o processo do morrer. Isto fica bem evidenciado no seguinte depoimento:

- Normalmente o momento da morte é complicado, mas no caso de doente com uma doença maligna, o mais sofrido, o mais complicado é o caminho para a morte.

Tentaremos acompanhar o processo de morrer em crianças com câncer através da análise das falas dos oncologistas entrevistados. Neste caminho, o primeiro momento - o início da via-crúcis - é o momento do diagnóstico. Como sabemos a palavra câncer é carregada metaforicamente de sentido de morte. Segundo um entrevistado,

- Desde a primeira consulta trava-se um diálogo com a morte. A morte deixa de ser aquela coisa abstrata e distante e passa a ser algo concreto e próximo, representada, muitas vezes, ali, por aquela pessoa que está dizendo: "você tem câncer". 
A partir do diagnóstico surge o primeiro dilema na abordagem da criança portadora de uma doença maligna, isto é, decidir se ela deve ou não ser comunicada. Segundo os oncologistas entrevistados, sempre há uma tentativa de comunicar à criança, ou explicar através de uma linguagem compreensível, o que está acontecendo com ela. Primeiro, porque a mesma vai ter de ser submetida a um tratamento muito agressivo; segundo, porque ela acaba percebendo, por atitudes e comportamentos dos pais, que alguma coisa muito grave está acontecendo. Posteriormente, através de várias internações, vai adquirindo a consciência da morte, observando que outras crianças com problemas semelhantes morrem.

- Eu tento sempre explicar na linguagem da criança. Eu acho que é o mínimo que podemos fazer se vamos submetê-la a um tratamento superagressivo como o nosso. Eu digo: "olha, você tem um caroço que vai fazer uma guerra com você. É como os inimigos do Jaspion, eles são poderosos, e a gente tem de usar armas poderosas pra lutar". Quer dizer, eu tento, através de uma fantasia, para que a criança entenda o que está acontecendo com ela $e$ entenda o tratamento.

Outro ponto crítico constatado, o qual gera muita angústia para os médicos, é a questão do tratamento oncológico, sua agressividade e a questionável qualidade de vida por ele muitas vezes determinada. Vejamos o seguinte depoimento:

- O tratamento oncológico é muito agressivo, os efeitos da medicação são muito fortes. Muitas vezes os pacientes querem abandonar o tratamento, principalmente os adolescentes, eles às vezes, abandonam. Acho que o nosso papel é esclarecer que embora agressivo, ele é a arma de que dispomos para esta batalha. Fora disso não se pode garantir nada. Ninguém sabe o que é capaz de acontecer dentro da cabeça dos pacientes. Mas o que se pode presumir em caso de abandono é que o tumor vai evoluir e crescer, e eu procuro deixar isso bem claro pra eles.

Todo esse caminho da criança com doença maligna é vivenciado com muito sofrimento. Existe um despreparo para lidar com essa situação, o que muitas vezes leva a um distanci- amento, que freqüentemente é responsável pela reação mais comum e aceita no meio médico: o "não envolvimento" :

- Eu tento encarar a coisa de uma maneira muito fria. É minha maneira de me defender. Eu procuro não me envolver muito, eu dou apoio pra família mas de maneira muito discreta, muito de fora, fico à distância.

Alguns profissionais reagem de forma diferente, assumindo o sofrimento e tentando conviver com os sentimentos despertados pela situação da morte, evitando um superenvolvimento que possa prejudicar seu lado profissional e igualmente evitando um posicionamento frio e desumano que possa comprometer sua relação com todas as pessoas envolvidas e com seu próprio senso de realização profissional:

- Eu percebo que sinto muita dor em partilhar o sofrimento do meu paciente. Tem algumas crianças que só de pensar nelas me faz sofrer. Acho importante deixar que o paciente perceba isso, que você tem emoções em relação à própria morte dele, que inevitavelmente vai te fazer sentir impotente, fracassado. Eu procuro deixar claro que eu não estou alheia a todo aquele sofrimento. Afinal, você também é humano. Muitas vezes os próprios colegas não aceitam isso, rotulam de antiprofissional, e isso te reprime, você fica se policiando.

Analisando estes depoimentos, podemos concluir que a convivência diária com pacientes ameaçados de morte gera, nos médicos, uma imensa angústia. Esta angústia obriga o médico a patinar entre duas condutas. A primeira, que, como vimos, seria a atitude mais aceita e considerada "profissional", é freqüentemente assumida, sendo caracterizada por um posicionamento frio e técnico. A segunda postura possível, menos freqüente, consiste em tentar se aproximar do paciente e compartilhar com ele seu sofrimento. Esta última postura é, com certeza, mais humana e afetiva, porém traz em si, como a primeira, a representação da morte como um fracasso e nossa incapacidade de vivência-la de outra forma, como constata Ziegler (1977:238):

"A identificação extrema entre o médico e o moribundo, que se realiza às vezes junto ao 
leito do hospital, procede de um movimento convergente de duas inteligências e é extremamente desejável. Mas o que se pode esperar da convergência de duas inteligências fundamentalmente alienadas, que nada possuem em comum senão a sua comum alienação? (...) Seria preciso que houvesse disponível no seio da sociedade mercantil um saber existencial do destino humano, que se comunicaria de um homem ao outro, conferindo àquele que o recebesse uma irredutivel dignidade e uma paz. infinita. (...) A sociedade mercantil destruiu o homem. (...) O moribundo não sabe morrer e o médico é incapaz de lhe explicar o sentido da morte. O processo de morrer, ato essencial de toda existência humana, deixa de ser uma aventura assumida para tornar-se uma eventualidade absurda, sofrida na ignorância".

\section{A VIVÊNCIA DOS HOMEOPATAS}

Inicialmente, é importante esclarecer que o objetivo de se fazer uma análise de diferentes vivências, como a de oncologistas, médicos de emergência, médicoos de de CTI e homeopatas, transcende à discussão terapêutica alopatia versus homeopatia.

Na realidade ,o que se busca é um contraponto filosófico em relação à concepção de morte, à abordagem de pacientes terminais e do próprio processo de morrer.

A filosofia postula que o objetivo do tratamento homeopático é tratar integralmente o indivíduo e restabelecer seu equilíbrio, atuando sobre uma gama de sintomatologia não apenas, no seu aspecto material e orgânico, mas também toda uma sintomatologia dinâmica que se reveste de uma forma dinâmica de processo morboso.

A cura homeopática devolve à energia vital o seu equilíbrio, sua euritmia, mas nem por isso o paciente curado homeopaticamente adquire a tão sonhada imortalidade:

"E mesmo a este homem que tenha recebido o medicamento Simillimum só se pode considerar relativamente são, porque deve enfrentar a necessidade de compreender, aceitar e aderirse ao que de incurável tem a sua enfermidade básica - a vida temporal: morte, vulnerabili- dade, imperfeição de seu meio e incerteza sobre o certo, ou seja, seu instinto religioso de eternidade" (Mazi, 1982:11-12).

O conceito mais marcante neste grupo é a concepção de "cura energética", mesmo na impossibilidade de uma reversão da entidade clínica. Este conceito possibilita o aparecimento de uma nova representação nova: morrer curado. Isto confronta a representação tradicional de "fracasso" e pode ser evidenciado nos seguintes depoimentos:

- E o paciente recupera a saúde até mesmo na vigência de um câncer, que está fazendo ele morrer. E ele morre saudável.

- O grande guia do medicamento homeopático é o bem-estar do paciente. A homeopatia não vai evitar a morte. Se o paciente tiver que morrer, ele vai morrer da doença, porém de uma forma mais tranqüila, mais suave, curado. (...) A gente lida pouco com doente terminal, mas o olhar do homeopata muda. Mesmo se a gente está num CTI ou emergência, o olhar é diferente e se baseia no bem-estar do paciente. Por isso, para nós, homeopatas, muitas das tentativas desesperadas de prolongar a vida a todo o custo são inconcebiveis.

Nos depoimentos dos homeopatas entrevistados foi possível detectar conceitos relacionados ao questionamento filosófico religioso presente na doutrina homeopática. Neste grupo, em contraste com os demais, surge uma marcante concepção espiritualista:

- Nestes momentos, você tem que dar algo a mais. Você precisa saber o que significa a morte, pois a pessoa precisa de um apoio espiritual para aquele momento que ela vai viver. Você precisa ajudá-la a sentir que a morte não termina nada, é apenas uma modificação de estado. É uma continuidade daquilo que você é, do que você já foi e daquilo que você sente.

O principal contraponto de reflexão é a abordagem de pacientes terminais. Por um lado, a maioria dos médicos reconhece uma tendência de afastamento e desinvestimento em relação a estes pacientes, tendência esta decorrente da concepção de que não há mais a fazer, são "casos perdidos". Já os homeopatas discordam, 
afirmando que sempre deve-se perseguir a cura homeopática. Segundo eles, mesmo pacientes terminais e agonizantes poderiam contemplar tal cura. Isto pode não evitar a morte, mas representa a garantia de uma morte tranqüila. Neste sentido, as diferenças conceituais são tão marcantes que a forma como é vivenciado o momento da morte pode ser utilizada como avaliação da qualidade do tratamento prestado, como assinala o depoimento a seguir:

- Muitas vezes a gente se dá conta do resultado do tratamento prestado pelo momento da morte, como ele é vivenciado. Eu tive um paciente adolescente que morreu de AIDS. Eu fui vê-lo em casa, ele não podia andar. O medicamento homeopático possibilitou uma melhora e ele foi me procurar no consultório. A forma como ele se apresentou foi inacreditável, suas reações, os seus sentimentos. Eu senti que ele foi fundo e atingiu um estado de compreensão que me surpreendeu. Eu sei que ele morreu em paz e curado. Eu aprendi muito com ele.

\section{CONSIDERAÇÕES FINAIS}

A partir do processo de reflexão desencadeado por este trabalho, podemos ressaltar alguns pontos que foram revelados pela pesquisa.

Em primeiro lugar, podemos concluir que, na Medicina, a problemática da morte nada mais é que a derivação de uma questão da Filosofia e das concepções de vida e de morte em nossa cultura. A vida é sempre vista separada da morte, a qual é concebida e vivenciada como um fracasso.

Nos depoimentos dos médicos entrevistados, percebemos a dificuldade sempre presente em lidar com a morte e com o processo de morrer dos pacientes, dificuldade esta exacerbada pela falta de discussão decorrente da omissão das escolas médicas frente a este questionamento. Neste sentido, assinalamos e destacamos, apoiados pela unanimidade dos depoimentos, a importância desta discussão a nível de formação médica, mesmo correndo o risco de que um tema tão importante seja "engolido" pela ideologia de um sistema que não concebe a sua importância.

Existe uma preocupação, a qual foi possível evidenciar nas falas dos médicos, em relação à desumanização de sua prática. No entanto, esta questão parece ser externa à sua vivência cotidiana e, principalmente, ao processo de formação médica, que não questiona - ao contrário, incentiva - uma visão mecanicista da vida do homem.

Não é difícil concluir que é desumana, fria, técnica e impessoal a forma de morrer hoje em nossa sociedade. As pessoas próximas e queridas — família e amigos — são afastadas e substituídas por uma parafernália eletrônica. Porém, não há como deixar de reconhecer o espaço e a importância deste aparato tecnológico.

É importante que os médicos sejam despertados e conscientizem-se da necessidade deste questionamento. Os avanços tecnológicos colocam nas suas mãos o poder e a decisão de mudar o tempo de vida das pessoas, e toda a sociedade, de maneira geral, precisa refletir sobre isso.

Penso que este é um dos caminhos para tornar a vivência da morte menos solitária e angustiante para as pessoas envolvidas. E se nos empenharmos um pouco, quem sabe esta relação não se torna mais humana e digna?

\section{RESUMO}

\section{HOFFMANN, L. A Morte na Infância e sua} Representação para o Médico - Reflexões sobre a Prática Pediátrica em Diferentes Contextos. Cad. Saúde Públ., Rio de Janeiro, 9 (3): 364-374, jul/set, 1993.

A morte - essa certeza presente direta ou indiretamente em algum momento da vida de todo ser humano - tem sido, especialmente no século XX, um tema proibido, negado, esquecido.

Os médicos, apesar de uma experiência mais próxima com a morte, através da sua vivência profissional cotidiana, não conseguem se familiarizar com ela; pelo contrário, o confronto com a morte sempre desperta sentimentos conflitantes de fracasso, culpa, impotência.

Através da análise e reflexão de diferentes vivências, principalmente frente à crucialidade da morte na infância, buscou-se compreender 
a representação deste momento na vida do médico.

Apesar do tradicional silêncio das escolas médicas frente a este questionamento, assinala-se, com o apoio da unanimidade dos entrevistados, a importância da introdução de discussões sobre a morte e o morrer no processo de formação do médico, com o objetivo de compreender a morte enquanto parte integrante da vida e promover a humanização do atendimento aos pacientes terminais e seus familiares.

Palavras-Chave: Atitude Frente a Morte; Ética Médica; Papel do Médico; Pediatria; Morte, Criança

\section{REFERÊNCIAS BIBLIOGRÁFICAS}

ARIÈS, P., 1982. O Homem Diante da Morte. Rio de Janeiro: Francisco Alves.

, 1988. Sobre a História da Morte no Ocidente desde a Idade M édia. Lisboa: Teorema.

BALTZEL, W., 1971. The dying patient. When the focus must be changed? Archives of Internal M edicine, 127: 106-109.

BARTON, D.; FLEXNER, J.; Van EYS, J.; SCOTT, C. E., 1972. Death and dying a course for medical students. Journal of Medical Education, 47: 945-951.

CONCONE; M. H. V. B., 1983. O "Vestibular" de anatomia. In: A M orte e Os M ortos na Sociedade B rasileira (J. S. Martins, org.), pp. 25-37, São Paulo: Hucitec.

HAHNEMANN, S., s/d. Exposición de la Doctrina M édica Homeopática ú Organon del Arte de Curar. Madri: Imprenta de D. Ignacio Boix.
HOFFMANN, L., 1991. Os Médicos e a M orte na Infância - Representação de um Tema Interditado. Tese de Mestrado, Rio de Janeiro: Instituto Fernandes Figueira, Fundação Oswaldo Cruz.

KUBLER-ROSS, E. (Org.), 1981. M orte Estágio Final da Evolução. Rio de Janeiro: Record. , 1989. Sobre a M orte e o M orrer. São Paulo: Martins Fontes.

MARTINS, J. S. (Org.), 1983. A M orte e os M ortos na Sociedade Brasileira. São Paulo: Hucitec.

MAUKSCH, H. O., 1981. O contexto organizacional do morrer. In: Morte Estágio Final da Evolução (E. Kubler-Ross, org.), pp. 33-52, Rio de Janeiro: Record.

MAZI, A., 1982. Conferência no Primeiro Curso de Homeopatia Unicista. Rio de Janeiro: Instituto Hahnemaniano do Brasil. (Mimeo.)

MEAGHER, D. K. \& Left, P. T., 1987. In Maries Memory: the rights of the child with life threatening of terminal illness. OMEGA, 20: 177-191.

MINAYO, M. C. S, 1989. O Desafio do Conhecimento: Metodologia de Pesquisa (qualitativa) em Saúde. Tese de Doutorado, Rio de Janeiro: Escola Nacional de Saúde Pública, Fundação Oswaldo Cruz.

RODRIGUES, J. C., 1983. Tabu da Morte. Rio de Janeiro: Achiamé.

SAPIR, M., 1972. La Information Psychologique du $M$ édecin. Paris: Payot.

ZAIDHAFT, S., 1990. M orte e Formação M édica. Rio de Janeiro: Francisco Alves.

ZIEGLER, J., 1977. Os Vivos e a Morte. Rio de Janeiro: Zahar. 